Per cent. S present $\ldots \ldots \ldots, 0.46$

Per cent. $S$ found......... 0.45

$$
\left.\begin{array}{l}
0.914 \\
0.91 \\
0.90 \\
0.92
\end{array}\right\}
$$$$
\text { I. } 37
$$

2.29

0.98

1.96

CONCLUSION.

The results of all tests show that the method carried out in accordance with the above directions, is accurate to within a few hundredths of a per cent., and is so rapid that an average of two or even three complete determinations per hour can be accomplished. It can be used with especial advantage where large numbers of sulphur determinations are required, since in such a case its saving in time and in the use of platinum becomes an important item.

The method can be successfully employed not only for the determination of sulphur in coals, but also, with suitable modifications, for the determination of small percentages of sulphur in a large number of organic and inorganic substances.

LABORATORY OF THE SOIVAY PROCESS Co., SYRACCSE, N. Y.

\title{
ON TRIPHENYLMETHYL ACETATE.
}

By M. Gomberg and G. T. Davis.

Received October I2, 1903 .

HEMILIAN, ${ }^{1}$ the discoverer of triphenylcarbinol, observed that the carbinol reacts with acetyl chloride, giving rise to hydrochloric acid and a crystalline mass which, on exposure to moist air, loses acetic acid and changes back to the carbinol. With acetic anhydride and with benzoyl chloride he obtained unstable esters, which were readily decomposed by water and by alcohol. Later, Allen and' Kölliker ${ }^{2}$ described a method for the preparation of triphenylmethyl acetate, which consisted in the action of acety! chloride upon triphenylcarbinol ethyl ether,

$$
\begin{aligned}
&\left(\mathrm{C}_{6} \mathrm{H}_{3}\right)_{3} \mathrm{C}-\mathrm{O}-\mathrm{C}_{2} \mathrm{H}_{5}+ \mathrm{CH}_{3} \mathrm{COCl}= \\
&\left(\mathrm{C}_{6} \mathrm{H}_{5}\right)_{3} \mathrm{C}-\mathrm{O}-\mathrm{OCCH}_{3}+\mathrm{C}_{2} \mathrm{H}_{5} \mathrm{Cl} .
\end{aligned}
$$

They claim to have identified the escaping gas as ethyl chloride, and give the melting-point and the solubilities, as well as the

1 Ber. d. chem. Ges.. 7, 1207 (1874).

2 Ann. Chem. (Liebig), 227, I16 (1885). 
analysis, of the acetate. Recently, Herzig and Wengraf, ${ }^{1}$ in connection with their studies on the acetyl derivatives of aurin, rosolic acid and benzaurin, repeated the experiments described by Hemilian, and by Allen and Kölliker in regard to the acetyl compound. Herzig and Wengraf find that the acetyl derivative, as obtained by them, possesses greater stability than ascribed to it by Hemilian. They also claim that the original method of Flemilian, the action of acetyl chloride directly upon the carbinol, is to be preferred to the method of Allen and Kölliker, who employed the triphenylcarbinol ethyl ether instead of the carbinol itself. Hemilian, as well as Herzig and Wengraf, concluded that the product described by them was the acetyl derivative, because, on treatment with water, the carbinol was regenerated, apparently by saponification. With alcohol, the acetyl compound gave the triphenylcarbinol ethyl ether, the reaction being the reverse of that which gave Allen and Kölliker the acetyl derivative,

\section{$\left(\mathrm{C}_{6} \mathrm{H}_{5}\right)_{3} \mathrm{C}-\mathrm{O}-\mathrm{OCCH}_{3}+\mathrm{C}_{2} \mathrm{H}_{5} \mathrm{OH}=$}

$$
\left(\mathrm{C}_{6} \mathrm{H}_{5}\right)_{3} \mathrm{C}-\mathrm{O}-\mathrm{C}_{2} \mathrm{H}_{5}+\mathrm{CH}_{3} \mathrm{COOH} \text {. }
$$

It is on the basis of the above-mentioned researches that the statements in the literature ${ }^{2}$ in regard to triphenylmethyl acetate are made. In the following pages it will be shown that the reactions described by the different investigators lead, not to the formation of the acetyl derivative but simply to that of triphenylchlormethane; that the acetyl compound, prepared by us by an indirect method, possesses properties different from those assigned to it by others, and that the acetyl compound could not exist under the conditions of the experiments which were used for its preparation.

Action of Acetyl Chloride.-One of us reported ${ }^{3}$ that by treating triphenylcarbinol ethyl ether with acetyl chloricle pure triphenylchlormethane was obtainerl. The discrepancy between these results and thcse of Allen and Kölliker, who claimed to have obtained, by this reaction, triphenylmethyl acetate, necessitated a careful tevision of the experiments.

1 Monatsh. Chem., 22,612 (1901).

2 "Beilstein," Ir, 1083 ; V. Meyer u. P. Jacobson, "Lehrbuch," II, 2, 109: "Richter." 3rd Ed., 353 ; Remsen's "Organic Chemistry," 355; Baeyer u. Villiger : Ber. $d$. chem. Ges.. 35,3015 , etc.

3 'This Journal, 24,6r8 (rgo2). 
(I) The ethoxy compound, $\left(\mathrm{C}_{6} \mathrm{H}_{5}\right)_{3} \mathrm{C}-\mathrm{OC}_{2} \mathrm{H}_{5}$, was made by boiling triphenylchlormethane with absolute alcohol. The product was recrystallized once from alcohol and twice from petroleum ether. The substance was thus obtained in pure white crystals, melting sharply at $83^{\circ} \mathrm{C}$. To 2 grams of this ethoxy compound was added an amount of freshly distilled acetyl chloride just sufficient for solution, and the mixture was boiled for about an hour. Upon cooling slowly, large white crystals, I.5 grams, separated. After recrystallization, the product gave a melting-point of I $2^{\circ} \mathrm{C}$., and was identified by its properties and by analysis as pure triphenylchlormethane.

(2) Two grams of the ethoxy compound were dissolved in cold acetyl chloride. A small amount of heat was generated by the reaction, and crystallization commenced at once. A little petroleum ether was added and the mixture cooled in ice. The crystals, I.8 grams, were washed with petroleum ether, recrvstallized and analyzed. They melted at $\mathrm{III}^{\circ} \mathrm{C}$., and consisted of pure triphenylchlormethane. An analysis gave I2.9I per cent. chlorine; calculated, 12.75 per cent.

(3) The triphenylcarbinol, instead of the ethoxy componnd, was next tried. Two grams were dissolved in acetyl chloride. The solution was of a violet color and changed to a dark red as the reaction progressed. Some heat was evolved in this reaction also. The crystals which separated on cooling, r.7 grams, showed, on recrystallization, a melting-point of $109^{\circ} \mathrm{C}$., and were found to consist of pure triphenylchlormethane. The analysis gave 12.67 per cent. chlorine.

The action of acetyl chloricle upon triphenylcarbinol and upon its ethoxy compound is, therefore, as follows :

$$
\begin{aligned}
& \left(\mathrm{C}_{6} \mathrm{H}_{5}\right)_{3} \mathrm{C}-\mathrm{O}-\mathrm{C}_{2} \mathrm{H}_{5}+\mathrm{CH}_{3} \mathrm{CO} \cdot \mathrm{Cl}= \\
& \left(\mathrm{C}_{6} \mathrm{H}_{5}\right)_{3} \mathrm{C}-\mathrm{Cl}+\mathrm{CH}_{3} \mathrm{COOC}_{2} \mathrm{H}_{5} . \\
& \left(\mathrm{C}_{6} \mathrm{H}_{5}\right)_{3} \mathrm{C}-\mathrm{O}-\mathrm{HI}+\mathrm{CH}_{3} \mathrm{CO} \cdot \mathrm{Cl}= \\
& \left(\mathrm{C}_{6} \mathrm{H}_{5}\right)_{3} \mathrm{C}-\mathrm{Cl}+\mathrm{Cli}_{3} \mathrm{COOH} .
\end{aligned}
$$

Action of Acetic Anhydride.-(I) One gram of the pure carbinol was boiled for an hour with pure acetic anhydricie. The acid was then distilled off under diminished pressure and the residue recrystallized from petroleum ether. The product, 0.9 gram, melted at $160^{\circ} \mathrm{C}$, and was found to consist of unchanged carbinol. 
(2) Another sample of triphenylcarbinol was boiled with acetic anhydride and anhydrous sodium acetate. The solution was filtered hot and concentrated, as before, under diminished pressure. The resulting product, which melted at $159^{\circ} \mathrm{C}$., was again unchanged carbinol.

Herzig and Wengraf obtained, on boiling the reaction product from acetic anhydride and the carbinol with alcohol, triphenylcarbinol ethyl ether. But, as they themselves observe, this cannot be taken as a conclusive proof that the acetyl compound was the cause of its formation, because the carbinol itself gives, on boiling with alcohol in presence of a small amount of acetic acid, the ethyl ether compound. The experiments described above show that in reality no acetyl compound was formed. ${ }^{1}$

Triphenylmethyl Acetate. -We next prepared the acetyl compound by an indirect method,-by the action of silver acetate upon triphenylchlormethane. Four grams of triphenylchlormethane were dissolved in berizene, mixed with an excess of silver acetate and boiled, with reflux condenser, for two hours, moisture being carefully excluded. The solution was filtered hot and the excess of benzene distilled off. The crystals, which separated out on cooling with ice, were washed with petroleum ether and then recrystallized, twice from petroleum ether and twice from acetic ether. The melting-point of the crystals remained constant at $87^{\circ}-88^{\circ} \mathrm{C}$. 'I he analysis gave:

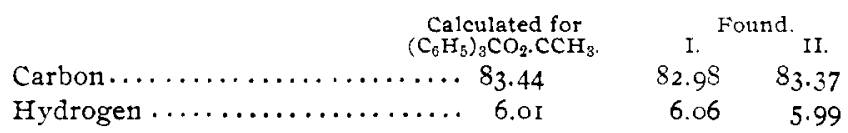

The acetyl group was determined in the ustual manner, by boiling the substance with an alcoholic solution of potassium hydroxide and titrating the excess of the alkali with a standard solution of acid. Calculated for $\left(\mathrm{C}_{0,} \mathrm{H}_{n}\right): \mathrm{CO}_{0} \mathrm{OCCH}$, acetyl, $\mathrm{I} 5.25$ per cent.; found, I3.Ig and I 3.07 per cent.

We have also prepared the acetyl compound without the employment of heat. One sample of triphenylchlormethane was suspended in absolute ether, an excess of silver acetate added, and the whole shaken for three weeks at the temperature of $25^{\circ} \mathrm{C}$. A second sample, dissolved in benzene, was treated in the same way. In both instances, almost quantitative yields of very pure

i Compare Bistrzycki und Herbst: Ber, d. chem. Ges., 35, 3 I33 (Ig02). 
triphenylmethyl acetate were obtained. The acetyl compound melts, as stated, at $87^{\circ}-88^{\circ} \mathrm{C}$. It is very soluble in the usual organic solvents, and, like so many other triphenylmethyl derivatives, shows a tendecy to separate from concentrated solutions in the form of an oil, which, on scratching, changes to a crystalline mass. Acetic ether gives the best appearing crystals. The compound is readily decomposed by water and by alcohol.

Action of Acetic Acid upon the Acetyl Compound.-It was found by one of us $^{1}$ that triphenylchlormethane reacts but slowly with cold glacial acetic acid, but quite appreciably when the solution is heated. It was also found ${ }^{2}$ that hydrochloric acid acts upon triphenylcarbinol in acetic acid even when the latter contains as much as to per cent. water, and gives triphenylchlormethane. It was suggested that while in a 90 per cent. acetic acid solution the reaction is a reversible one in regard to carbinol (I), in absence of water it is similarly so in regard to the acetyl compound (II).

$$
\begin{aligned}
&\left(\mathrm{C}_{6} \mathrm{H}_{3}\right)_{3} \mathrm{C} \cdot \mathrm{Cl}+\mathrm{H}_{2} \mathrm{O} \underset{(}{\rightleftarrows}\left(\mathrm{C}_{6} \mathrm{H}_{5}\right)_{3} \mathrm{C} \cdot \mathrm{OH}+\mathrm{HCl} \\
&\left(\mathrm{C}_{6} \mathrm{H}_{5}\right)_{3} \mathrm{C} \cdot \mathrm{Cl}+\mathrm{CH}_{3} \mathrm{COOH} \underset{(}{\rightleftarrows}\left(\mathrm{C}_{6} \mathrm{H}_{5}\right)_{3} \mathrm{CO} \cdot \mathrm{COCH}_{3}+\mathrm{HCl}
\end{aligned}
$$

Experiment, however, shows that this is not the case in (II). Two grams of triphenylchlormethane were heated with a large excess of carefully purified glacial acetic acid on the water-bath, and a constant stream of dry carbon dioxide was passed through the solution for twenty hours. A careful examination of the residue, obtained on removing the acetic acid under diminished pressure, showed that, in addition to some triphenylchlormethane, it contained triphenylcarbinol, but none of the acetyl compound.

Action of Acetyl Chloride upon the Acetyl Compound.-The acetyl chloride for this experiment was carefully fractionated. A stream of thoroughly dried carbon dioxide was then passed through the chloride in order to free it completely from any hydrochloric acid gas which it might have contained in solution. One-half gram of pure triphenylmethyl acetate was gently warmed with the acetyl chloride. The excess of the liquid was removed in a stream of dry air, and the crystalline residue was dried in a vacuum dessicator over soda-lime. It melted at $109^{\circ} \mathrm{C}$, and proved to be pure triphenylchlormethane. The analysis gave I 2.97 per cent. chlorine; calculated, I2.75 per cent.

1 Ber. d. chem. Ges., 36, 379 (1903).

2 Ibid., 36, 384 (1903). 
As Hemilian, Allen and Kölliker, and Herzig and Wengraf have all used acetyl chloride in the preparation of the substance described by them an triphenylmethyl acetate, and as the latter is decomposed by that reagent, it follows that the substance dedescribed by them as triphenylmethyl acetate, and as the latter It was, we believe, triphenylchlormethane. The latter would give, on treatment with water or with alcohol, the same products as the acetyl componnd: the carbinol or the ethoxy compound. In fact, this is true of all the salts of thiphenylmethyl: the halides, the sulphate, the picrate, etc., are readily hydrolyzed.

AxN ARbor, Mich.

September, 1903 .

\section{ON THE POSSIBLE EXISTENCE OF A CLASS OF BODIES ANALOGOUS TO TRIPHENYLMETHYL.}

[PRELIMINARY NOTICE.]

BY MI, GOMBERG.

Keceived October I2, 1903 .

IN TIL: several papers which I have published cn the subject of triphenylmethyl, some important features in regard to the behavior of that substarce were brought out.

(I) The extreme unsaturation of the compound, as evidenced by the action of atmospheric oxygen and of iodine upon it.

(2) The unusual property possessed by that unsaturated hydrocarbon of entering into combination with different oxygen compounds, such as ethers, esters, etc. It appeared probable that these combinations represent compounds wherein the oxygen acts as being tetravalent. It might be added here that triphenylmethyl unites with equal readiness with nitriles.

(3) Triphenylmethyl may be considered as a distinctly basic rarlical. This furnishes an explanation why triphenylchlormethane, also the bromide and the iodide, are salts, as judged by their purely chemical behavior, as well as by the physicochemical tests; these halides, dissolved in liquid sulphur dioxide, are true electrolytes. ${ }^{1}$ The same is true of the sulphate, as was found by Mr. L. H. Cone ${ }^{2}$ in this laboratory. Even triphenyl-

1 Gomberg: Ber. a. chem. Ges., 35, 2403 (1902); Walden : Ibial, 35, 2018 (1902).

${ }_{2} \mathrm{Mr}$. L. H. Cone, holder of a research assistantship to the Carnegie Institution, will publish his results in full later. 